now challenges. Ringwood maintains that the upper-mantle $\mathrm{Mg} / \mathrm{Si}$ ratio is representative of the bulk Earth. His arguments in favour of a chemically homogeneous terrestrial mantle are based on results of experiments on the partitioning of major and trace elements between high-pressure phases that are stable in the deep interior of the Earth and silicate melt.

Crystallization and gravitational settling of such phases from a completely or partially molten terrestrial mantle would preferentially incorporate certain elements, such as aluminium or hafnium. The residual mantle should then be deficient in these elements. Because samples from the upper mantle, accessible to laboratory analyses, do not show this depletion, Ringwood concludes that differentiation of the Earth's mantle has not occurred. Ringwood then postulates, contrary to assumptions that he and others have previously made, that the bulk-Earth (upper mantle) $\mathrm{Mg} / \mathrm{Si}$ ratio, and not the CI ratio, is identical to the solar ratio.

Ringwood offers in support of his hypothesis systematic studies of the $\mathrm{Mg} / \mathrm{Si}$ ratio in various objects in the Solar System. He concludes that the inner planets - Earth, Moon, Venus, Mars and the parent planet of a group of closely related basaltic and ultramafic meteorites (possibly derived from the asteroid Vesta) - could all have higher $\mathrm{Mg} / \mathrm{Si}$ ratios than the Orgueil meteorite. On the other hand, low $\mathrm{Mg} / \mathrm{Si}$ ratios are found not only in $\mathrm{CI}$ chondrites: there is evidence that interplanetary dust particles (IDPs) recovered from the stratosphere by $\mathrm{U} 2$ aircraft have similar or even lower ratios. Also, chemical data on the composition of dust particles from comet Halley obtained by European and Soviet spacecraft indicate a low $\mathrm{Mg} / \mathrm{Si}$ ratio there. Because the inner planets including the Earth have the solar $\mathrm{Mg} / \mathrm{Si}$ ratio according to Ringwood's hypothesis, CI-chondrites, IDPs and comets, having lower $\mathrm{Mg} / \mathrm{Si}$ ratios, should be enriched in $\mathrm{Si}$.

A common feature of CI chondrites, IDPs and comet Halley is that they are rich in volatile elements and it is therefore assumed that they formed at low temperatures in cooler outer parts of the solar nebula. Because $\mathrm{Si}$ is, under most conditions, more volatile than $\mathrm{Mg}$, a high content would be consistent with high contents of volatiles.

Ringwood supposes that during formation of the terrestrial planets, volatile elements - including a small fraction of Si - would be lost and later recondense on material in the outer part of the solar nebula. The amount of Si lost would have to be so small that the terrestrial planets would still retain the solar $\mathrm{Mg} / \mathrm{Si}$ ratio.

Although $\mathrm{Mg} / \mathrm{Si}$ ratios can be reliably determined in CI meteorites, it may seem impossible to determine such a ratio precisely for a bulk planet from the analysis of a few differentiated surface rocks. However, one must realize, as Ringwood points out, that small differences in this ratio may reflect large variations in the ratio of the two important $\mathrm{Mg}$ and $\mathrm{Si}$ bearing minerals, olivine, $\mathrm{Mg}_{2} \mathrm{SiO}_{4}$ with an $\mathrm{Mg}$ / $\mathrm{Si}$ ratio of 2 and orthopyroxene, $\mathrm{MgSiO}_{3}$ with a ratio of 1 . Basalts, partial melts extruded on the surface of a planet, are accessible to direct or remote chemical analysis. As the chemical composition of basalts is primarily determined by the mineralogy of their source region it is a sensitive indicator for the $\mathrm{Mg} / \mathrm{Si}$ ratios in the deep interior.

As with all such models, some of Ringwood's assumptions are open to challenge. Most importantly, the opinions on the question of a chemically homogeneous terrestrial mantle are divided. D. Anderson (California Institute of Technology) has consistently pointed out that the velocity of seismic waves travelling through the mantle requires a more Si-rich lower mantle. Other modellers still believe they can accommodate melting and crystallization of the mantle with constraints obtained by the partitioning data of Kato et al. ${ }^{3}$. Furthermore, the possibility that some $\mathrm{Si}$ was removed from the mantle during the formation of the core cannot be excluded (see Laura Garwin's News and Views report ${ }^{4}$ for a discussion of this).

In addition, one may argue that a volatility-related 20 per cent excess of $\mathrm{Si}$ in CI chondrites, should result in correspondingly greater excesses of more volatile elements than $\mathrm{Si}$, such as sulphur, sodium and potassium. The agreement between abundances in the solar photosphere and in Orgueil for these elements would then have no significance.

Although details of the model may be questioned, some kind of chemical stratification of the solar nebula is probably required to understand variations in the chemistry of meteorites, comets and the inner planets. The importance of Ringwood's approach lies in the attempt to relate the composition of the Earth to that of other Solar System materials and to try to understand chemical variations in terms of a uniform model of Solar System evolution. This type of modelling will become increasingly important in the future as new compositional data on Solar System objects become available.

H. Palme is in the Max-Planck-Institut for Chemistry. Saarstrasse 23, 6500 Mainz, FRG.

1. Ringwood, A. E. Earth planet. Sci. Lett. 95. 1-7 (1989)

2. Anders, A \& Grevesse, N. Geochim. Cosmochim. Acta $\mathbf{5 3}$ $197-214$ (1989)

Kato, T. et al. Earth planet. Sci. Lett. 89, 123 (1988)

4. Garwin, L. Nature 338, 19-20 (1989).

5. Jagoutz, E. et al. Proc. 10th Lunar Planet Sci. Conf. 2031 2050 (1979)

6. Ringwood, A.E. Composition and Petrology of the Earth's Mantle (McGraw Hill, New York, 1975).

7. Sun, S.-S. Geochim. Cosmochim. Acta 46, 179 (1982)

8. Paime, H. \& Nickel, K.G. Geochim. Cosmochim. Acta 49 , $2123-2132\{1985$

\section{The cold smoulder}

Most big cities are unattractive places these days. As social harmony and civic pride decline, their inhabitants increasingly disfigure them with litter and graffiti, which depress civic pride even more. Daedalus now proposes a technical fix.

He has been inspired by those catalytic surfaces which burn up organic deposits. Many metallic and metal-oxide surfaces are excellent oxidation catalysts at elevated temperatures - they are used in those ovens which rapidly burn off grime and spilt food. Some carefully optimized surfaces can oxidize selected organics at $100{ }^{\circ} \mathrm{C}$ or even lower. So he is devising a catalytic pavement, the DREADCO 'Catwalk', to oxidize paper, plastics and so on, at room temperature.

As a low-temperature catalyst, Catwalk will absorb atmospheric oxygen very readily. The tricky problem is activating the organic litter lying on it. Daedalus points out that solid surfaces are always microscopically rough. They touch each other at only very few points, where the contact pressure is extremely high. The pressureactivated molecules at these points should therefore oxidize easily, by a form of catalytic stress corrosion. As fast as they burn away, the unsupported solid will subside upon their successors, which will oxidize in their turn.

Instead of the few milliseconds of contact time needed for high-temperature catalysis, this low-temperature variant will take hours or days to degrade a piece of litter. But ultimately anything organic - torn newspaper, discarded fast-food wrapper, cigarette end, painted slogan or offensive sticker - will slowly burn to ash, or partially oxidize to some rain-soluble mixture of aldehydes and polyols.

Once perfected, 'Catwalk' and its vertical counterpart 'Catawall' should make a city almost vandal proof. The graceless, resentful citizens will chuck their garbage on its streets, or degrade its hideous architecture still further with graffiti, only to see their exertions rapidly nullified. They may rejoice in this endless renewal of their creative canvas; but just possibly they may reform, and take pride in their new, smart environment.

Catwalk and Catawall will have intriguing side-effects. Shoe soles and tyres will rapidly oxidize away, and may need to be replaced by inorganic or silicone-based substitutes. Street-corner loungers will lose the shoulders of their jackets, and dogs will have to wear bootees. Hygiene will be wonderfully enhanced. The universal dusty detritus of life, hair and fibre and food fragments and general organic dirt, and the bacteria and cockroaches and mice that live on it, will simply oxidize and disappear. The urban environment will be almost surgically clean.

David Jones 